\title{
USING ANALYTIC HIERARCHY PROCESS TO WEIGHT DIFFERENT OBJECTIVES OF TIMETABLING PROBLEM
}

\author{
Müjgan Sağır Özdemir \\ Osmangazi University Engineering and Architecture Faculty \\ Industrial Engineering Department Eskisehir Turkiye \\ mujgano@,ogu.edu.tr
}

Key words: Timetabling, analytic hierarchy process, qualitative factors, solution quality

\begin{abstract}
Summary: Timetabling is a regular activity to be performed prior to the commencement of each academic term or year. The problem is of interest mainly due to its large size, complex requirements and varied nature. Since it has many conflicting requirements, the solution process mostly aims at obtaining a feasible solution. Besides, the problem has a multiobjective structure. These objectives are also usually in conflict and it is difficult to find a solution that optimizes each one. In this case, determining the priorities or the weights of the objectives is very important and these parameters directly affect the solution quality. This study includes a university timetabling. Analytic hierarchy process is used to weight different objectives of the problem. Different criteria and the related sub criteria are defined in different levels. The main steps of the study can be summarized as developing a hierarchy model, paired comparisons, weighting, comparing of three feasible timetables, and discussing the results.
\end{abstract}

\section{Introduction}

Typical elements of the timetabling problem are participants, availabilities and meetings which define a binary relation between participants and availabilities. The timetabling problem may be defined as the task of schedule a given set of meetings in a limited number of time slots called periods so that certain constraints are satisfied. The problems range from the construction of weekly timetables in secondary schools, colleges and universities through to the timetabling of transport facilities such as buses, trains or aircraft. However, it is in the area of educational timetabling that most attention has been focused with continued interest. (Johnson, 1993). Moreover, even for a single institution, there are many different types of timetabling problem: Scheduling courses, rooms, examinations, etc. Almost every school has its own particular rules and preferences regarding the way in which its courses are timetabled. There are always multiple objectives to be considered. Some of these are a wholly practical nature but others, equally important, are more qualitative issues related to important educational requirements and preferences (Wright, 1996).

In the light of the above explanations two important factors are considered as main reasons for this study: Firstly, the solution quality and applicability of any optimization problem depend on its model and the model parameters. We have qualitative factors as much as the quantitative ones in the problems although the qualitative factors are difficult to measure. So they are ignored in many cases. The second factor is the weighting of different objectives of a timetabling problem.

This study concerns a university timetabling problem including students, faculty and school administration. Analytic Hierarchy Process (AHP) is used to weight different objectives of the problem. The constraints can be considered among the objectives and we may have them in the hierarchy. But this study concentrates on the objectives for simplification and the aim here is to show how their weights can be used to evaluate a timetable. 
The main steps of the study can be summarized as, defining criteria and sub criteria of the problem, developing a hierarchy model, paired comparisons, weighting, comparing three timetables and discussing the results.

\section{Defining the Criteria of the Problem}

Sixteen criteria are defined to represent different objectives of the problem. For example, "minimum course conflicts", is an objective related to the "conflicts" criterion. Each participant has different objectives. The participants' attitudes towards timetables were evaluated with self-administrated questionnaires answered by 252 students, 49 faculties and 14 school administrators from different departments of an engineering faculty. By combining these results with the previously performed literature survey (Özdemir, 1998), the following criteria are derived as listed in Table 1.

Table 1. Criteria Used to Judge Timetable Alternatives

\begin{tabular}{|r|l|r|l|}
\hline $\mathbf{1 .}$ & $\begin{array}{l}\text { Number of students } \\
\text { registered in a course }\end{array}$ & $\mathbf{9 .}$ & Free day \\
\hline $\mathbf{2 .}$ & Pedagogical convenience & $\mathbf{1 0}$ & Weekend class \\
\hline $\mathbf{3 .}$ & Teaching load & $\mathbf{1 1}$ & Classroom capacity \\
\hline $\mathbf{4 .}$ & Conflicts & $\mathbf{1 2}$. & Classroom location \\
\hline $\mathbf{5 .}$ & Course instructor & $\mathbf{1 3}$ & Instructor preferences \\
\hline $\mathbf{6 .}$ & Uniform distribution & $\mathbf{1 4}$ & Students' daily load \\
\hline 7. & Classroom requirements & $\mathbf{1 5}$. & $\begin{array}{l}\text { Previous and following } \\
\text { courses of a course }\end{array}$ \\
\hline $\mathbf{8 .}$ & Lunch time & $\mathbf{1 6}$ & Predetermined assignments \\
\hline
\end{tabular}

A brief definition of each criterion can be given as :

Number of students

registered in a course : Large courses in which numerous students are registered should be grouped.

Pedagogical convenience: The number of gaps should be minimum. As far as possible theoretical lessons should be scheduled in the morning etc.

Teaching load : The number of lessons per day and per week for an instructor is an important factor. It is not preferred to exceed a specified limit.

Conflicts

: If two courses of a student are held simultaneously for at least one hour, they are in conflict. The aim is to have a timetable with minimum conflicts.

Course instructor $\quad:$ It is an important factor especially for the students.

Uniform distribution : Lessons of the same course should be distributed uniformly over the week.

Classroom requirements: Courses should be assigned to suitable classrooms. Some subjects may be taught in especially equipped classrooms with TV monitors, slide projectors, etc.

Lunch time

: A slot of time, for example one hour, is reserved for lunch every day for the participants.

Free day

Weekend class

Classroom capacity

: Students and instructors prefer to have more lessons on some days, in order to have a day without lessons.

: Students and instructors do not prefer to have a course on weekends.

Classroom location

: A classroom with fewer seats than students is undesirable, as is one that is too large.

$\begin{array}{ll} & \begin{array}{l}\text { department should be minimum. Sufficient time must be provided for } \\ \text { students to move from one building to another, if necessary. }\end{array} \\ \text { Instructor preferences } \quad \text { : Allowing instructor preferences in course selection. }\end{array}$ 


$\begin{array}{lll}\begin{array}{l}\text { Students' daily load } \\ \begin{array}{l}\text { Previous and following } \\ \text { courses of a course }\end{array}\end{array} & \begin{array}{l}\text { The number of lessons per day for a student should not exceed a specified } \\ \text { limit. }\end{array} \\ \begin{array}{l}\text { Predetermined } \\ \text { assignments }\end{array} & \begin{array}{l}\text { The sequence of courses must be respected (labs must follow lectures, etc.) } \\ \text { Students should not be lectured theoretical lessons consecutively. }\end{array}\end{array}$

\section{Developing a Hierarchy for the Criteria}

A model of the problem is developed using a hierarchical representation. At the top of the hierarchy is the overall goal or prime objective one is seeking to fulfill. Then, the relevant attributes of the decision problem, such as selection criteria and the various "actors" (individuals, agencies and organizations), if appropriate, that provides significant input on the decision process take place. For the timetabling problem the goal is to have the optimum timetable. The criteria are grouped into three main categories as related to the courses, classrooms and the others. Three criteria related to course criterion are also grouped as the subcriteria of a new criterion defined as day and time slot. Consequently, the first group, which is called the course branch, has five criteria. These are number of students registered in a course, previous and following courses of a course, conflicts, the instructor, and the day and time slot of a course. The day and time slot criterion has three subcriteria as pedagogical convenience, weekend course, and uniform distribution of the courses over the days. The second group, the classroom branch, contains the criteria about the physical properties of the classroom such as the capacity, the location and the classroom requirements. The last branch is "the others" criteria. This includes free day, lunch time, predetermined assignments, instructor preferences, teaching load and the students' daily load.

\section{Paired Comparisons and Weighting}

Once a hierarchy is generated, one needs to determine the "potency of influence" of the factors at a particular level of a hierarchy on the next higher level, over all levels. In the AHP applications the number of levels in the hierarchy depends on the complexity of the problem. For this problem the participants were not included in the hierarchical representation directly, but they were included in the paired comparison process. A group including one administrator, one instructor and two students performed a brain storming to discuss the criteria and their paired comparisons. Five paired comparisons need to be performed. The first one consists of three main criteria, course, classroom and the others. The second one is for the five subcriteria under the course criterion. For example, these second paired comparisons allow the procedure to establish local weights for these five criteria, which must sum to one. The higher the local weights for a criterion the more important that criterion is in the decision making process. Similarly, paired comparisons must be performed for all three criteria under classroom criterion and for six criteria under the others criterion and finally, for three criteria under the day and the time slot of a course subcriterion.

To keep the paper within a reasonable length, all the paired comparisons are not given here, except the one related to the course criterion as shown in Table 2. In particular, consider the criterion of the "conflicts" along with the one of the "instructor". The decision maker must answer the following question. With respect to "course" criterion, how much more important is the confliction of a course with another one than the instructor of this course? The answer is 2 for this case. 
Table 2. The Paired Comparisons for the Course Criterion

\begin{tabular}{|c|c|c|c|c|c|}
\hline & 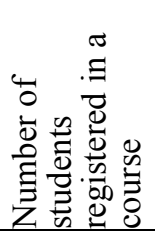 & 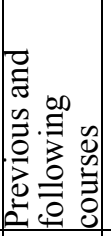 &  & 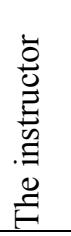 & 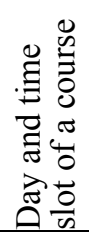 \\
\hline $\begin{array}{l}\text { Number of students } \\
\text { registered in a course }\end{array}$ & 1 & $1 / 2$ & $1 / 6$ & $1 / 3$ & $1 / 6$ \\
\hline $\begin{array}{l}\text { Previous and } \\
\text { following courses }\end{array}$ & 2 & 1 & $1 / 4$ & $1 / 3$ & $1 / 4$ \\
\hline Conflicts & 6 & 4 & 1 & 2 & 1 \\
\hline The instructor & 3 & 3 & $1 / 2$ & 1 & $1 / 2$ \\
\hline $\begin{array}{l}\text { Day and time slot of a } \\
\text { course }\end{array}$ & 6 & 4 & 1 & 2 & 1 \\
\hline
\end{tabular}

Our ability to make qualitative distinctions is well represented by five intensities: equal, moderate, strong, very strong, and extreme. We can make compromises between adjacent intensities when greater precision is needed. Thus we require nine values which should be consecutive. The scale is given in Table 3 (Saaty, 2000).

Table 3. The Scale for Paired Comparisons

\begin{tabular}{|c|c|c|}
\hline $\begin{array}{l}\text { INTENSITY OF } \\
\text { IMPORTANCE }\end{array}$ & DEFINITION & EXPLANATION \\
\hline 1 & Equal importance & Two activities contribute equally to the objective \\
\hline 3 & Moderate importance & $\begin{array}{l}\text { Experience and judgment slightly favor one activity } \\
\text { over another }\end{array}$ \\
\hline 5 & Strong importance & $\begin{array}{l}\text { Experience and judgment strongly favor one activity } \\
\text { over another }\end{array}$ \\
\hline 7 & $\begin{array}{c}\text { Very strong or } \\
\text { demonstrated importance }\end{array}$ & $\begin{array}{l}\text { An activity is favored very strongly over another; its } \\
\text { dominance demonstrated in practice }\end{array}$ \\
\hline 9 & Extreme importance & $\begin{array}{l}\text { The evidence favoring one activity over another is of } \\
\text { the highest possible order of affirmation }\end{array}$ \\
\hline $2,4,6,8$ & Average intensities & \\
\hline
\end{tabular}

The paired comparisons result in an influence matrix. Once the influence matrix is determined, the "Eigenvalue method" is employed to determine the local priorities or the weights $\left(w_{i}\right)$ for a group of criteria (Cambron, 1991). These priorities are determined by solving

$$
\begin{aligned}
& A_{w}=\lambda_{\text {max }} w \\
& \sum_{i} w_{i}=1 \\
& w=\left(w_{1}, w_{2}, \ldots, w_{n}\right)
\end{aligned}
$$

where $w$ is the $n$ dimensional eigenvector associated with the largest eigenvalue, $\lambda_{\max }$, of the influence matrix, $A$. $\lambda_{\max }$ is determined by selecting the largest value of $\lambda$ that satisfies the equation given by: 


$$
|A-\lambda I|=0
$$

The influence matrix, $A=\left(a_{i j}\right)$, is given by: (Cambron, 1991)

- The answers provided by the decision maker for $i<j$,

- 1 , for $i=j$, and

- $1 / a_{i j}$ for $i>j$.

In the light of the above explanations, the local priorities determined for these five branches of the "course" criterion are $0.053,0.082,0.339,0.184$ and; 0.339 respectively. Associated with the local priorities is the concept of an inconsistency ratio. Suppose that a decision maker states that factor 1 is more important than factor 2 and factor 2 is more important than factor 3 ; it is expected that factor 1 is more important than factor 3 . But if the decision maker states that factor 3 were more important than factor 1 , we would say that he is inconsistent. The inconsistency ratio is a measure of this inconsistency. If this ratio is less than 0,1 it means that the judgments are acceptable. Otherwise the decision maker must reconsider his paired comparisons. The inconsistency ratio (I.R.) is obtained by forming the ratio of the consistency index (C.I.) and the appropriate one of a set of numbers, each of which is an average random consistency index (R.I.). The consistency index is given by

$$
\left(\frac{\lambda_{\max }-n}{n-1}\right)
$$

For this example C.I. $=0.0098$. The inconsistency ratio is $0.008\left(n=5, R . I .=1,11, \lambda_{\max }=5.0392\right.$, and

$$
\text { I.R. }=\frac{0.0098}{1.11}=0.008
$$

The global weights of these criteria are obtained via multiplying each local weight by 0.59 that is the global weight of the course criterion. The results are $0.031,0.049,0.2,0.11$, and 0.2 respectively. All the paired comparisons yield the global weights as shown in Figure 1.

\section{Comparing Three Timetables by Using Defined Criteria}

Once all of the weights for all factors in the hierarchy have been determined, a "synthesis" is performed. That is, each of the alternatives are scored. In this study, three different timetables are compared, TT1, TT2 and TT3, for an industrial engineering departments' fall semester. For example to compare the alternatives for "conflicts" criterion, three paired comparisons should answer the question: Which candidate has the minimum confliction among the courses in the timetable and how much better when compared with another candidate? The paired comparison matrix for this criterion is given in Table 4. 




Figure 1. The Hierarchy 
Table 4. Comparison of Timetables with respect to Conflicts Criterion

\begin{tabular}{|c|c|c|c|c|}
\hline & TT1 & TT2 & TT3 & Local weights \\
\hline \hline TT1 & 1 & $1 / 3$ & 1 & 0,21 \\
\hline TT2 & 3 & 1 & 2 & 0,55 \\
\hline TT3 & 1 & $1 / 2$ & 1 & 0,24 \\
\hline \multicolumn{5}{|c|}{ I.R. $=0,017$} \\
\hline
\end{tabular}

In Table 5, the local weights of the three candidates for each of the corresponding criteria are given. We then weight each row by the priority (global weights) of the criteria above it and sum to obtain the overall weights on the right. In this case the second timetable (TT2) would be selected with the highest priority, 0.410 .

Table 5 Comparison of Timetables with respect to the Sixteen Criteria

\begin{tabular}{|c|c|c|c|c|c|c|c|c|c|c|c|c|c|c|c|c|c|}
\hline & 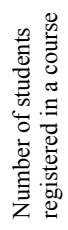 &  & 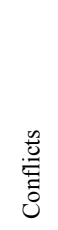 & 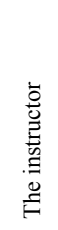 & 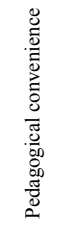 & 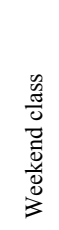 & 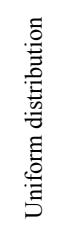 & 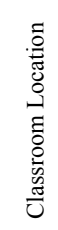 & 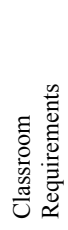 & 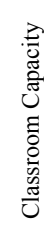 & 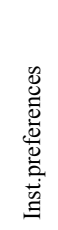 &  & 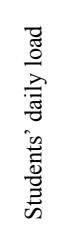 & 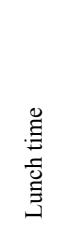 &  & 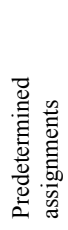 & 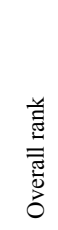 \\
\hline & 0.031 & 0.049 & 0.2 & 0.11 & 0.14 & 0.039 & 0.021 & 0.039 & 0.039 & 0.012 & 0.029 & 0.083 & 0,079 & $\mathbf{0 , 0 3 4}$ & 0,061 & $\mathbf{0 , 0 3 4}$ & \\
\hline TT1 & 0.16 & 0.33 & 0.21 & 0.54 & 0.16 & 0.50 & 0.33 & 0.43 & 0.19 & 0.33 & 0.63 & 0.54 & 0,25 & 0,14 & 0,20 & 0,41 & 0,313 \\
\hline TT2 & 0.30 & 0.33 & 0.55 & 0.30 & 0.54 & 0.25 & 0.33 & 0.43 & 0.58 & 0.33 & 0.24 & 0.30 & 0,25 & 0,57 & 0,40 & 0,33 & 0,410 \\
\hline TT3 & 0.54 & 0.33 & 0.24 & 0.16 & 0.30 & 0.25 & 0.33 & 0.14 & 0.23 & 0.33 & 0.13 & 0.16 & 0,50 & 0,29 & 0,40 & 0,26 & 0,275 \\
\hline I.R. & 0.008 & 0.00 & 0.017 & 0.008 & 0.008 & 0.00 & 0.00 & 0.00 & 0.051 & 0.00 & 0.017 & 0.008 & 0,00 & 0,051 & 0,00 & 0,051 & \\
\hline
\end{tabular}

\section{Conclusions}

Finding a feasible course schedule is not an easy task. Conflicts due to courses, instructors' availabilities, geographical and time windows requirements have to be taken into account. So, it is usually considered a feasibility problem rather than an optimization problem. However, there is a quality aspect of the solutions.. When one tries to measure the quality of two timetables, there are different, somehow unrelated, characteristics to be compared. Usually, a unique cost function is defined. Anyway, it is clear that the solution of an optimization problem does strictly depend on the determination of its parameters.

In this study analytic hierarchy process is used to weight different objectives of timetabling problem. Sixteen criteria are defined. A hierarchy model was developed. The paired comparisons and their inconsistency tests were performed. Then three feasible timetables were compared by using the criteria weights. 
There are always other criteria that can be implemented in order to improve the institution way of life. The hierarchy presented here is only one possible arrangement of criteria. In a timetabling problem the constraints and the participants also can be considered among the objectives. But in this study we just concentrated on objectives for simplification and it is aimed to discuss how their weights can be used to evaluate a feasible timetable.

There are many areas of application of the AHP such as planning, setting priorities, measuring performance, optimizing, predicting outcomes and, allocating resources. This study prioritized different objectives of the timetabling problem. In this manner it is as an application of AHP for setting priorities. On the other hand timetabling problem is defined as the task of schedule a given set of meetings in a limited number of time slots called periods so that certain constraints are satisfied. As we mentioned before, we did not consider the constraints. But AHP can also be used as a resource allocation tool to assign meetings to the time slots with a different definition of the hierarchy.

\section{References}

Johnson, D. (1993), “A Database Approach to Course Timetabling”, Journal of the Operational Research Society, 44,5,425-433.

Wright, M.(1996), "School Timetabling Using Heuristic Search", Journal of the Operational Research Society, $47,347-357$

Özdemir, M.S. (1998), “A Two Phased Approach for Weekly Timetabling Problems”, Ph.D.Dissertation, Osmangazi University.

Cambron, K.E., Evans, G.W. (1991), "Layout Design Using the Analytic Hierarchy Process", Computers and Industrial Engineering, 20, 2, 211-229.

Thomas L.Saaty, (2000), Fundamentals of Decision Making and Priority Theory with the Analytic Hierarchy Process, Vol.VI of the AHP Series, RWS Publications, USA, 478 page. 